\title{
THEO DÕI HẠN HÁN TRONG MÙA KHÔ BÀ̀G CHỈ SỐ HẠN HÁN NDDI TRÊN CÔNG CỤ GOOGLE EARTH ENGINE, THÍ NGHIẸM TẠI TỈNH ĐĂK NÔNG
}

\author{
TỐNG THỊ HUYỀN ÁI ${ }^{(1)}$, NGUYẼ̃N PHÚC HẢI ${ }^{(1)}$, LÊ HŨU DỤNG ${ }^{(2)}$, \\ VÕ HỒNG HIỀN ${ }^{(3)}$, PHẠM TH!̣ LÀN ${ }^{(4)}$ \\ (I) Viện Công nghệ vũ trụ, Viện Hàn Lâm Khoa học và Công nghệ Việt Nam, \\ ${ }^{(2)}$ Chi nhánh Văn phòng Đăng ký đất đai huyện Cờ Đỏ, thành phố Cần Tho; tỉnh Cần Tho \\ ${ }^{(3)}$ Sở Tài nguyên và Môi trưòng tỉnh Bến Tre \\ ${ }^{(4)}$ Khoa Trắc địa-Bản đồ và Quản lý đất đai, Trường Đại học Mỏ Địa chất
}

\section{Tóm tắt:}

Trong nghiên cứu này, nhóm tác giả đã phân tích mối quan hệ giũa các chỉ số vật lý NDVI, NDWI và NDDI với múc độ hạn hán của tỉnh Đăk Nông. Dũu liệu ảnh Landsat trong mùa khô tù̀ năm $2005-$ 2019 arợc thu thập, tiền xủ lý và tính toán các chi số trên công cu Google Earth Engine một cách nhanh chóng. Các kết quả sau khi phân tích chỉ ra rằng, NDWI và NDDI có độ nhạy với hạn hán tốt hơn so với chỉ số NDVI. Trong đó, giá trị $N D D I>0,8$ và $N D W I<0,1$ là nhũng khu vưc ở múc độ hạn nhẹ. Chi số NDDI càng tăng thi khả năng xảy ra hiện tượng hạn hán càng cao. Do đó chỉ số này có thể được sử dụng nhu một chỉ báo để theo dõi và giám sát hạn hán cho tỉnh Đăk Nông trong mùa khô.

\section{1. Đặt vấn đề}

Hạn hán là một trong các hiện tượng tự nhiên của khí hậu. Hiện tượng hạn hán xảy ra ở hầu hết các quốc gia, cả những vùng khô cằn và ẩm ướt [1]. Bản thân hạn hán không phải là một thảm họa. Việc hạn hán có trở thành thảm họa hay không phụ thuộc vào tác động của nó đối với người dân địa phương, kinh tế, môi trường và khả năng đối phó, phục hồi từ hạn hán [2]. Mặc dù không có một định nghĩa chính xác và phổ biến nào về hạn hán bởi hiện tượng này thay đổi từ vùng này sang vùng khác và nó mang đặc điểm riêng của từng vùng. Nhìn chung, hạn hán là sự mất cân bằng giữa lượng mưa và sự thoát hơi nước trong một thời gian dài ở một khu vực cụ thể. Hạn hán thường xảy ra trong mùa khô cạn do đây là thời kỳ ít mưa, lượng dòng chảy trong sông suối cạn kiệt, trong khi lượng nước dùng cho sản xuất và sinh hoạt lại rất lớn. Nông nghiệp là ngành kinh tế bị ảnh hưởng đầu tiên khi hạn hán xuất hiện, bởi dấu hiệu ban đầu của hiện tượng này là sự thiếu hụt nước ở trong đất.

Trong những năm gần đây, Đăk Nông là một trong 5 tỉnh Tây Nguyên bị ảnh hưởng bởi hạn hán nghiêm trọng, nguồn nước trên sông suối hồ chứa cạn kiệt, mực nước ngầm xuống thấp, cây trồng thiếu nước dẫn đến năng suất và sản lượng giảm sút. Theo báo cáo tổng kết ngành nông nghiệp và phát triển nông thôn năm 2016, tổng diện tích cây trồng bị hạn là $18.548,58$ ha, giá trị thiệt hại vào khoảng 1.200 tỷ đồng. Trong khi số lượng trạm khí tượng để của tỉnh chỉ có 2 trạm, nên rất khó khăn để có thể theo dõi và dự báo hiện tượng hạn hán phục vụ cho hoạt động sản xuất của người dân trên toàn tỉnh.

Việc theo dõi và giám sát hạn hán thường dựa vào những quan sát thực tế từ các trạm khí tượng mặt đất [3]. Tuy nhiên, sự phân bố, mật độ của các trạm khí tượng không đủ để phát hiện thông tin không gian cần thiết, hơn nữa, các trạm này lại không liên tục và không kết nối được giữa các 
trạm với nhau. Do đó, để có thể giám sát cũng như đo đạc được những tác động của hạn hán, thì việc sử dụng dữ liệu ảnh vệ tinh đem lại hiệu quả tốt hơn khi chúng cung cấp thông tin cập nhật trong các phạm vi không gian và quy mô thời gian khác nhau. Số lượng vệ tinh quan sát trái đất và các sản phẩm dữ liệu ngày càng tăng cung cấp lượng dữ liệu lớn và phát triển các khả năng giám sát hạn hán tiên tiến bằng nhiều nguồn dữ liệu khác nhau. Tuy nhiên, theo truyền thống, việc thu thập, lưu trữ, định dạng tệp và xử lý dữ liệu vệ tinh là những trở ngại đáng kể để tận dụng tối đa các ảnh này, đặc biệt là trong các ứng dụng quy mô lớn và thời gian dài. Gần đây, một nền tảng điện toán đám mây miễn phí Google Earth Engine (GEE) cho phép lưu trữ và xử lý khối lượng lớn ảnh vệ tinh. Google Earth Engine có lợi thế trong việc theo dõi, giám sát sự thay đổi bề mặt đất trong khoảng thời gian dài ở khu vực lớn. GEE được ứng dụng nhiều trong theo dõi hạn hán thông qua các chỉ số hạn hán hay các biến liên quan đến hạn hán như mưa, nhiệt, ẩm, chỉ số thực vật [4].

Trong thời gian hạn hán, lá cây bị ảnh hưởng bởi hàm lượng nước có thể gây ra mất mùa hoặc giảm sản lượng cây trồng. Đối với việc theo dõi và cảnh báo sớm hạn hán bằng dữ liệu ảnh viễn thám, có rất nhiều các chỉ số vật lý đã được phát hiện để giám sát sức khỏe và sự tăng trưởng của thực vật [5]. Trong đó, dải phổ nhìn thấy (VIS) và hồng ngoại (IR) được sử dụng rộng rãi để theo dõi sự thay đổi của cây và căng thẳng nước. Chỉ số chuẩn hóa khác biệt thực vật NDVI - kết hợp của kênh cận hồng ngoại NIR và kênh đỏ, là chỉ số đo đạc sự thay đổi của hàm lượng Chlorophyll thực vật và độ xốp tán cây. Đây là chỉ số được sử dụng phổ biến trong giám sát hệ sinh thái [3]. Chỉ số chuẩn hóa khác biệt mặt nước NDWI có độ nhạy tốt với sự thay đổi về hàm lượng nước và độ xốp của tán cây [3] [6][7]. Chỉ số này được tính toán từ kênh cận hồng ngoại NIR và hồng ngoại sóng ngắn SWIR và được sử dụng để ước tính hàm lượng nước của tán cây trong các nghiên cứu về giám sát và cảnh báo sớm hạn hán. Sự kết hợp thông tin cả về thảm thực vật và nước được thể hiện qua chỉ số chuẩn hóa khác biệt hạn hán NDDI. Chỉ số NDDI này đã được chứng minh rằng có độ nhạy cao hơn về hạn hán trong mùa hè so với chỉ số NDWI và NDVI [2][3]. Do đó, nhóm nghiên cứu đã lựa chọn các chỉ số NDVI, NDWI và NDDI để theo dõi hạn hán tỉnh Đăk Nông trong mùa khô từ năm 2005 - 2019.

Mục tiêu của nghiên cứu này là đo đạc và theo dõi hạn hán từ dữ liệu ảnh Landsat khu vực tỉnh Đăk Nông từ năm 2005-2019 trên công cụ Google Earth Engine. Nghiên cứu này bao gồm các nội dung: 1- xây dựng chuỗi dữ liệu các chỉ số NDVI, NDWI từ ảnh Landsat, 2- đánh giá mối quan hệ giữa NDVI, NDWI, NDDI và số liệu khô hạn, 3- Phân vùng hạn hán tỉnh Đăk Nông từ chỉ số NDDI.

\section{Dữ liệu và phương pháp nghiên cứu}

\subsection{Khu vưc nghiên cúu và dĩ liệu}

Đăk Nông là một trong 5 tỉnh Tây Nguyên, nằm ở cuối dãy Trường Sơn, trọn vẹn trong khối cao nguyên cổ Đăk Nông - Đăk Mill chịu sự chi phối của khí hậu nhiệt đới gió mùa, vừa mang tính chất của khí hậu cao nguyên mát dịu. Song chịu ảnh hưởng mạnh nhất, chủ yếu nhất vẫn là khí hậu Tây Trường Sơn, đó là nhiệt độ trung bình không cao, mùa hè mưa nhiều, ít nóng bức do chịu ảnh hưởng của gió mùa Tây Nam, mùa đông mưa ít [8]. Khí hậu của Đăk Nông chia làm hai mùa rõ rệt, mùa khô bắt đầu từ tháng 11 năm trước đến tháng 4 năm sau, còn mùa mưa từ tháng 5- tháng 10. Sự mất cân đối về lượng mưa trong năm và sự biến động lớn về biên độ nhiệt ngày đêm và theo mùa đã ảnh hưởng rất lớn đến hoạt động sản xuất nông nghiệp của người dân. (Xem hinh 1) 
Google Earth Engine là một nền tảng xử lý không gian địa lý dựa trên đám mây để phân tích dữ liệu môi trường ở các quy mô khác nhau. Google Earth Engine (GEE) cung cấp nền tảng đám mây để truy cập và xử lý liền mạch số lượng lớn ảnh vệ tinh [4]. Trên công cụ GEE dữ liệu ảnh miễn phí có sẵn và được cập nhật liên tục như Landsat-8, MODIS, Sentinel,.... Đồng thời, cho phép tiền xử lý, tính toán, phân tích các chỉ số hạn hán để theo dõi và trực quan hóa mức độ hạn hán ở các khu vực khác nhau. Môi trường tương tác chính trên GEE là công cụ Code Editor: https://code.earthengine.google.com/ để phát triển các ứng dụng phân tích thông tin không gian địa lý. Giao diện lập trình của Code Editor cho phép người dùng tạo và chạy các thuật toán để xử lý ảnh một cách dễ dàng và nhanh chóng.

Dữ liệu ảnh Landsat có sẵn trên công cụ GEE được thu thập, chuẩn hóa và tổ hợp theo mùa khô (tháng 1- tháng 5) giai đoạn 2005 - 2019. Tập dữ liệu ảnh Landsat bao gồm Landsat $5 \mathrm{TM}$ và Landsat 8OLI được lọc với độ phủ mây dưới $20 \%$, thời gian từ $1 / 1-30 / 5$ từ năm 2005-2019 và cắt theo ranh giới tỉnh Đăk Nông trên công cụ
Code Editor của GEE. Trong đó, năm 2012 không thu được dữ liệu ảnh Landsat. Chuỗi dữ liệu Landsat sau khi thu thập và tiền xử lý sẽ là đầu vào cho việc tính toán các chỉ số vật lý. Kết quả của tập hợp dữ liệu chỉ số vật lý được so sánh và đánh giá tương quan với dữ liệu tính từ trạm khí tượng.

\subsection{Các chỉ số khô hạn}

Chỉ số chuẩn hóa khác biệt hạn hán NDDI (Normalized Difference Drought Index) được đề xuất từ năm 2007 bởi nhóm tác giả Yingxin GU [3] để đo đạc hạn hạn thông qua sự kết hợp thông tin của thực vật và mặt nước. Chỉ số NDDI được tính từ sự kết hợp của hai chỉ số chuẩn hóa khác biệt thực vật NDVI và chỉ số chuẩn hóa khác biệt mặt nước NDWI. (Xem bảng 1)

Hai chỉ số NDVI và NDWI được tính toán theo chuỗi thời gian trong mùa khô của tỉnh Đăk Nông từ năm 2005-2019 trên tập hợp dữ liệu ảnh Landsat bằng công cụ Google Earth Engine. Sau đó chỉ số NDDI được tính toán từ hai chỉ số NDVI và NDWI theo công thức số 3 .

Bên cạnh đó, thông tư số 14/2012/TTBTNMT của Bộ Tài nguyên và môi trường Ban

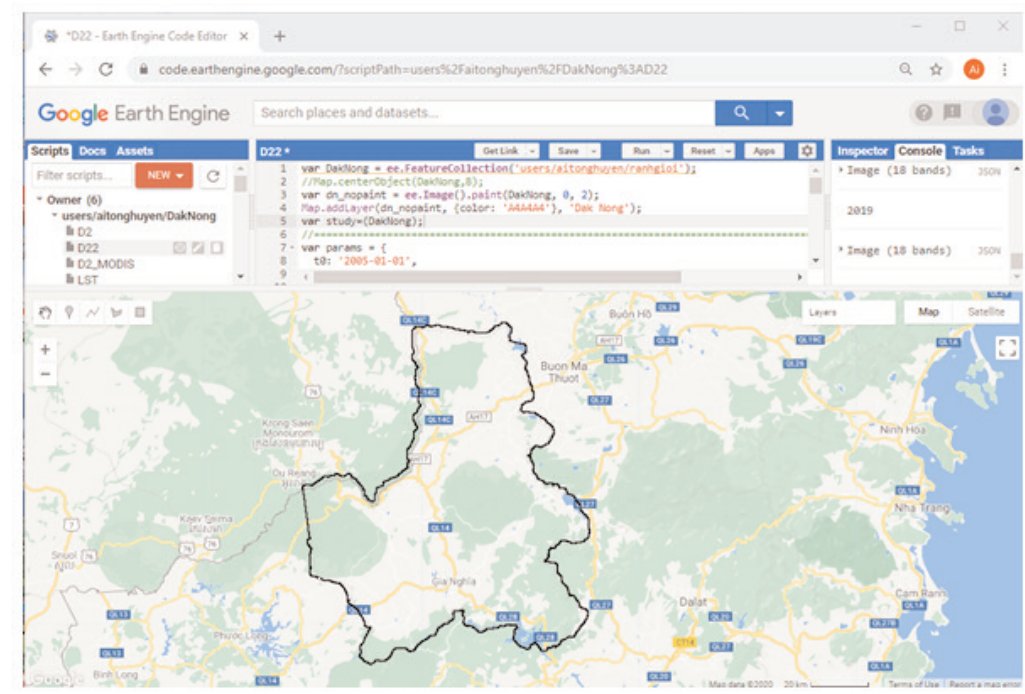

Hình 1: Ranh giới tỉnh Đăk Nông trên công cu Google Earth Engine 
hành quy định kỹ thuật điều tra thoái hóa đất đã đưa ra công thức tính toán chỉ số khô hạn Kth theo các trạm đo để xây dựng bản đồ đất bị khô hạn. Chỉ số khô hạn Kth này tính toán dựa vào tỷ lệ giữa lượng bốc hơi và lượng mưa với các số liệu thu thập từ trạm khí tượng của tỉnh Đăk Nông. Phân cấp ngưỡng khô hạn Kth như sau: (Xem bảng 2)

Số liệu thu thập tại hai trạm khí tượng cấp I là trạm Đăk Nông đặt tại thành phố Gia Nghĩa và trạm Đăk Mil nằm ở huyện Đăk Mil từ năm 2005 -2019 bao gồm dữ liệu mưa, bốc hơi từ Đài khí tượng thủy văn tỉnh Đăk Nông. Từ đó, tính toán và phân cấp khô hạn theo chỉ số khô hạn tháng Kth trung bình mùa khô theo từng năm từ 20052019. Giá trị chỉ số này được sử dụng để đánh giá mối tương quan với các chỉ số tính toán từ dữ liệu ảnh vệ tinh Landsat tổ hợp mùa khô các năm.

\section{Kết quả nghiên cứu và thảo luận}

\subsection{Dũ liệu khô hạn tại trạm khí tượng tỉnh Đăk Nông}

Tỉnh Đăk Nông có hai trạm khí tượng thủy văn cấp I là trạm Đăk Nông và trạm Đăk Mil thuộc sự quản lý của Đài khí tượng thủy văn tỉnh Đăk Nông. Số liệu thu thập và dùng để tính toán chỉ số khô hạn tháng theo Bộ Tài nguyên và môi trường bao gồm: số liệu mưa và bốc hơi theo tháng của hai trạm từ năm 2005-2019.

Hình 2 thể hiện giá trị khô hạn của chỉ số Kth trung bình mùa khô qua các năm theo số liệu khí tượng thu được tại hai trạm. Theo đó giá trị Kth của cả hai trạm tập trung trong khoảng giá trị từ 0,4 - 1,2 cho thấy tỉnh Đăk Nông phần lớn ở mức

Bảng 1: Công thức tính toán các chỉ số tù ảnh Landsat

\begin{tabular}{|c|c|c|c|c|}
\hline STT & Các chỉ số & Công thức & Phạm vi & $\begin{array}{c}\text { Nguồn tham } \\
\text { khảo }\end{array}$ \\
\hline 1 & $\begin{array}{l}\text { Chì số chuẩn hóa khác } \\
\text { biệt thực vật NDVI } \\
\text { (Normalized Difference } \\
\text { Vegetation Index) }\end{array}$ & $\begin{array}{l}(\lambda \text { nir }-\lambda \text { red }) /(\lambda \text { nir } \\
+\lambda \text { red })\end{array}$ & $-1>1$ & \\
\hline 2 & $\begin{array}{l}\text { Chì số chuẩn hóa khác } \\
\text { biệt mặt nước NDWI } \\
\text { (Normalized Difference } \\
\text { Water Index) }\end{array}$ & $\begin{array}{l}(\lambda \text { nir }-\lambda \text { swir }) \\
(\lambda \text { nir }+\lambda \text { swir })\end{array}$ & $-1>1$ & \\
\hline 3 & $\begin{array}{l}\text { Chì số chuần hóa khác } \\
\text { biệt hạn hán NDDI } \\
\text { (Normalized Difference } \\
\text { Drought Index) }\end{array}$ & $\begin{array}{l}\text { (NDVI - NDWI) } \\
(\text { NDVI + NDWI) }\end{array}$ & & $\begin{array}{l}\text { Bời Y. Gu } 2007 \\
\text { [3] }\end{array}$ \\
\hline 4 & $\begin{array}{l}\text { Chì số khô hạn tháng } \\
(\mathrm{K} \text { th })=\mathrm{K} 1\end{array}$ & $\begin{array}{l}\text { Lượng bốc hơi } \\
\left(\mathrm{E}_{0(\mathrm{th})}\right) / \text { Lượng } \\
\text { mưa }\left(\mathrm{R}_{(\mathrm{t})}\right)\end{array}$ & & $\begin{array}{l}\text { TT số } \\
\text { 14/2012/TT- } \\
\text { BTNMT [10] }\end{array}$ \\
\hline
\end{tabular}

Bảng 2: Bảng phân cấp đánh giá đất bị khô hạn theo chỉ số khô hạn tháng [10]

\begin{tabular}{|l|l|l|l|}
\hline STT & Mức độ khô hạn & Chì số khô hạn (K1) & Ký hiệu \\
\hline 1 & Không hạn & $<1$ & KhN \\
\hline 2 & Hạn nhẹ & $\geq 1-2$ & Kh1 \\
\hline 3 & Hạn trung bình & $\geq 2-4$ & Kh2 \\
\hline 4 & Hạn nặng & $\geq 4$ & Kh3 \\
\hline
\end{tabular}


độ không hạn hoặc hạn nhẹ. Tuy nhiên, giá trị này ngày càng tăng từ năm 2015 trở lại đây, điều này cho biết khả năng khô hạn của tỉnh có nguy cơ diễn ra nhiều hơn. Riêng năm 2016, giá trị khô hạn Kth ở khu vực trạm Đăk Mil là 2,4, tương đương với mức hạn trung bình.

Giá trị khô hạn Kth ở trạm Đăk Mil cao hơn so với trạm Đăk Nông, chỉ ra rằng ở khu vực Đăk Mil khô hạn hơn so với khu vực Đăk Nông. Trong vòng 14 năm thì ở trạm Đăk Mil có tới 8 năm nằm trong vùng hạn nhẹ, năm 2019 giá trị
Kth đạt gần mức hạn trung bình. Ở trạm Đăk Nông thì hiện tượng hạn nhẹ xảy ra vào các năm 2005, 2010 và 2019. Riêng năm 2019 thì giá trị Kth cao hơn so với năm 2010 có nghĩa mức độ hạn nhẹ cao hơn so với năm 2010. (Xem hình 2)

\subsection{NDVI, NDWI, NDDI và phân vùng khô} hạn cho toàn tỉnh

Hình 3 cho thấy mối quan hệ chặt chẽ giữa hai chỉ số NDVI và NDWI theo các mức độ khô hạn tại hai trạm Đăk Mil và Đăk Nông trung

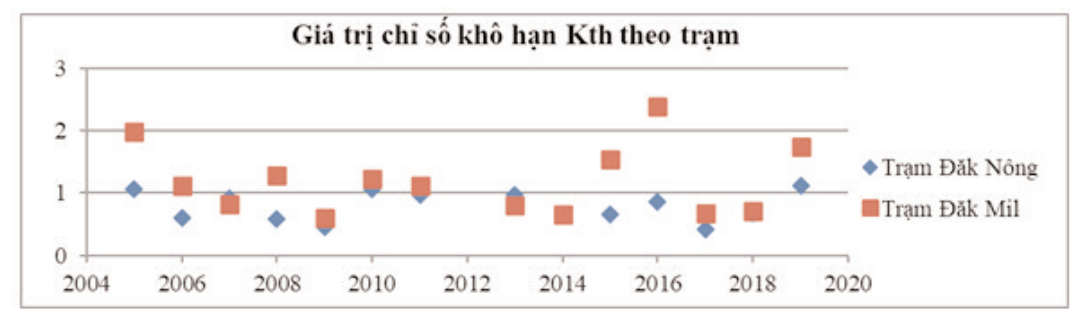

Hình 2: Giá trị chỉ số khô hạn Kth theo hai trạm khí tượng tỉnh Đăk Nông

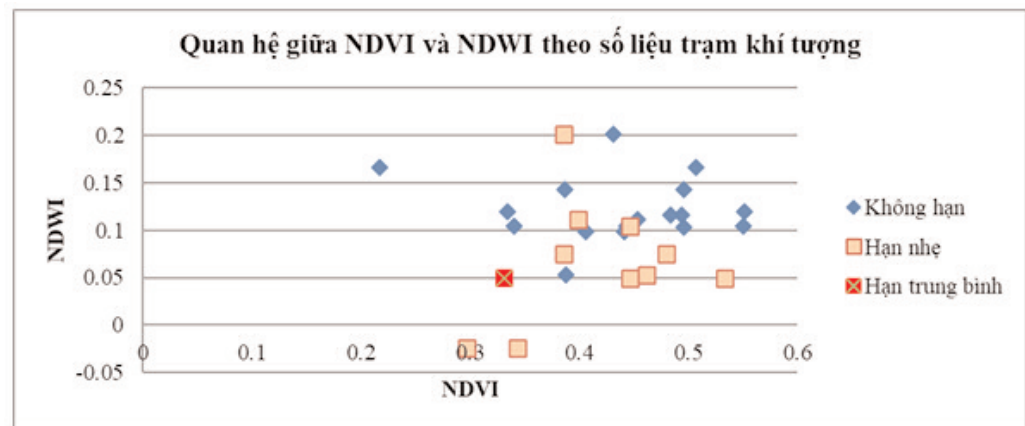

Hình 3: Mối quan hệ giữa NDVI và NDWI theo phân cấp khô hạn tỉnh Đăk Nông trung bình mùa khô tù năm 2005 - 2019

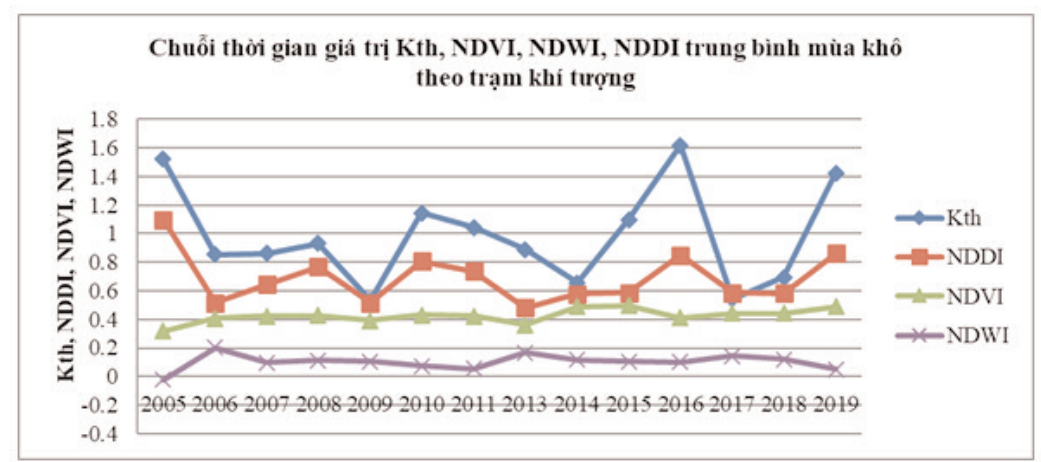

Hình 4: Giá trị Kth, NDVI, NDWI, NDDI trung bình mùa khô theo trạm 
bình mùa khô từ năm 2005 - 2019. Giá trị của NDVI và NDWI có mối tương quan nghịch với nhau, NDVI càng cao thì NDWI càng thấp. Giá trị NDVI $>0,4$ và NDWI $>0,1$ thuộc về những năm không hạn ở cả hai trạm khí tượng. NDWI thấp hơn 0,1 trong những năm còn lại được xác định là những năm hạn nhẹ. (Xem hình 3)

Chuỗi thời gian dữ liệu NDVI, NDWI, NDDI và Kth theo trạm tỉnh Đăk Nông được trình bày trong Hình 4. Trong mùa khô từ tháng 1 - tháng 5 từ năm 2005 - 2019, giá trị NDVI, NDWI,
NDDI và Kth luôn thay đổi theo giai đoạn. Giá trị Kth tăng và đạt đỉnh vào các năm 2005, 2010 , 2016 và 2019 là những năm hạn nhẹ, tương ứng là những năm có giá trị NDDI cao $>0,8$, trong khi giá trị NDWI thấp $<0,1$. (Xem hình 4$)$

Ở khu vực trạm Đăk Mil, vào những năm có hạn nhẹ giá trị NDDI cũng cao hơn so với trạm Đăk Nông. Giá trị NDDI trong từ năm 2013 trở lại đây cao hơn so với các năm cũ, tương ứng với giá trị NDVI và NDWI cũng thấp hơn ở trạm Đăk Mil. Trong khi ở trạm Đăk Nông, giá trị
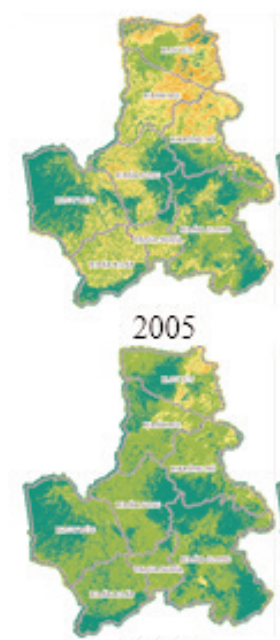

2009

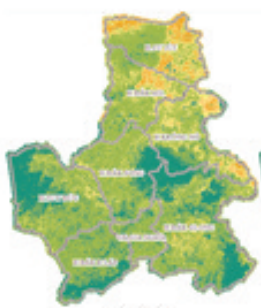

2014

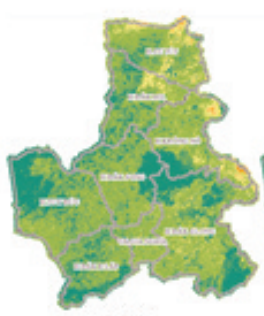

2018

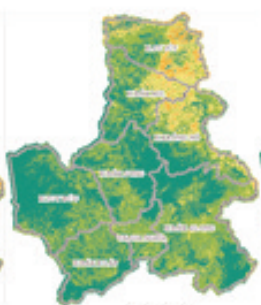

2006

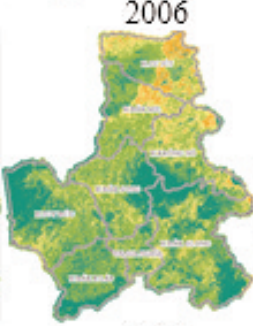

2010

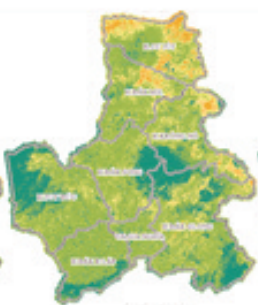

2015

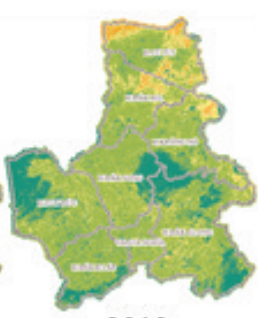

2019

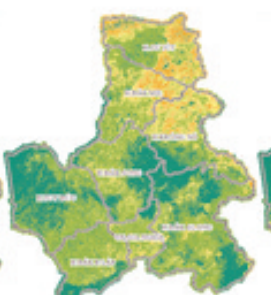

2007

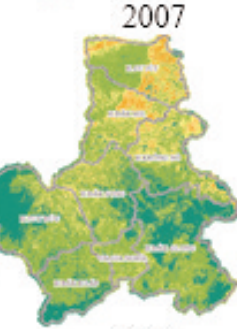

2011

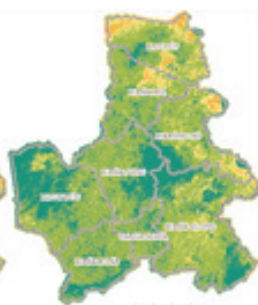

2016
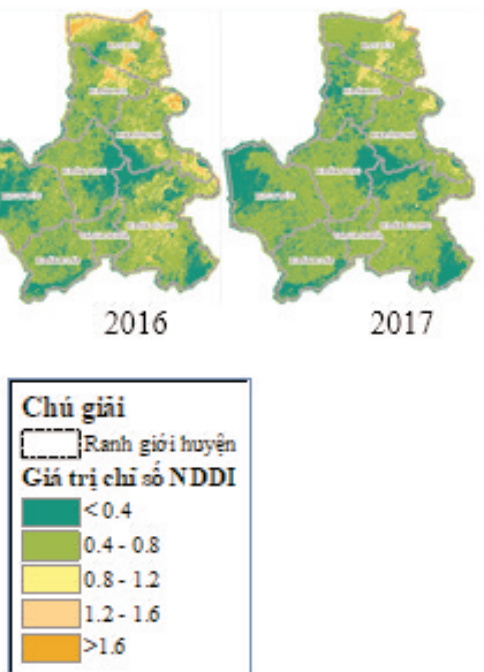

2017

Hình 5: Phân bố không gian của chỉ số NDDI qua các năm 
NDVIvà NDWI từ năm 2013 trở lại đây đều tăng và giá trị NDDI thấp. Điều này có nghĩa, chỉ số khô hạn NDDI cao ở những khu vực có lớp phủ thực vật giảm và lượng nước cũng giảm.

Giá trị của chỉ số NDDI đạt đỉnh vào các năm 2005, 2010, 2016 và 2019, tương ứng với giá trị của chỉ số NDWI thấp nhất và là những năm hạn nhẹ của tỉnh. Điều này cho thấy, NDDI và NDWI nhạy cảm hơn với điều kiện hạn hán so với chỉ số NDVI.

Sự phân bố của các giá trị chỉ số NDDI trung bình mùa khô tỉnh Đăk Nông qua các năm được hiển thị trong các Hình 5 bên dưới. Giá trị NDDI càng cao thì khả năng xảy ra hạn hán càng lớn. (Xem hinh 5)

Hình 5 cho thấy rằng, vào các năm 2005 , 2016 và 2019 , giá trị chỉ số hạn hán NDDI $>0,8$ dàn trải đều ra toàn tỉnh hơn so với các năm còn lại, tập trung vào 3 huyện phía Bắc của tỉnh. Từ năm 2014 trở lại đây, giá trị NDDI > 0,8 cũng mở rộng hơn so với các năm trước đó. Điều này chỉ ra rằng khả năng hạn hán xảy ra trên các khu vực này cao hơn và có quy mô ngày càng lớn.

\section{Kết luận}

Nghiên cứu này đã phân tích và đánh giá các chỉ số vật lý NDVI, NDWI, chỉ số hạn hán NDDI tính từ dữ liệu ảnh Landsat kết hợp với chỉ số khô hạn Kth từ số liệu hai trạm khí tượng thủy văn của tỉnh Đăk Nông từ năm 2005-2019.

Các chỉ số vật lý NDVI, NDWI và NDDI được tính toán trên công cụ Google Earth Engine một cách nhanh chóng và thuận lợi. Công cụ này cho phép thống kê và tổ hợp chuỗi dữ liệu ảnh Landsat từ tháng 1 - tháng 5 của tỉnh Đăk Nông từ năm 2005-2019 với số lượng lớn. Tập hợp dữ liệu ảnh Landsat sau khi thu thập được tiền xử lý và tính toán chỉ số theo các công thức trực tiếp trên công cụ Code Editor của Google Earth Engine.
Kết quả phân tích các chỉ số vật lý và chỉ số khô hạn cho thấy rằng, chỉ số NDVI và NDWI có mối tương quan chặt chẽ với mức độ khô hạn tại trạm. Trong mùa khô vào các năm 2005, 2016 và 2019 , hiện tượng hạn hán nhẹ xảy ra tương ứng với các giá trị $\mathrm{NDVI}<0,4, \mathrm{NDWI}<0,1$ và NDDI $>0,8$. Ở khu vực trạm Đăk Mil, giá trị của NDDI cao hơn so với trạm ở Đăk Nông, cho thấy khả năng xảy ra hạn nhẹ ở trạm Đăk Mil cao hơn so với trạm ở Đăk Nông. Trong đó, NDDI và NDWI nhạy cảm với hạn hán hơn so với chỉ số NDVI. Giá trị của NDDI trong những năm xảy ra hiện tượng hạn hán tăng lên chỉ ra rằng chỉ số này có thể được sử dụng như một chỉ báo để theo dõi và giám sát hạn hán cho tỉnh Đăk Nông trong mùa khô. $\bigcirc$

\section{Lò̀i cảm ơn}

Dữ liệu và kết quả của nghiên cứu này được hỗ trợ từ đề tài: "Nghiên cứu ứng dụng công nghệ viễn thám và GIS trong quản lý, đánh giá tổng hợp tài nguyên thiên nhiên và môi trường phục vụ phát triển kinh tế xã hội và du lịch tỉnh Đăk Nông”, mã số VT-UD.06/18-20 do TS. Lê Quang Toan (Viện Công nghệ vũ trụ) chủ nhiệm, nằm trong chương trình $\mathrm{KH} \& \mathrm{CN}$ cấp Quốc gia về Công nghệ Vũ trụ giai đoạn 2016-2020.

\section{Tài liệu tham khảo}

[1]. WMO and GWP, Handbook of Drought Indicators and Indices (M. Svoboda and B.A. Fuchs). Integrated Drought Management Programme (IDMP). Integrated Drought Management Programme (IDMP), Integrated Drought Management Tools and Guidelines Series 2. Geneva., no. 1173. 2016.

[2]. D. Renza, E. Martinez, A. Arquero, and J. Sanchez, "Drought Estimation Maps by Means of Multidate Landsat Fused Images," Remote Sens. Sci. Educ. Nat. Cult. Herit., pp. 775-782, 2010. 
[3]. Y. Gu, J. F. Brown, J. P. Verdin, and B. Wardlow, "A five-year analysis of MODIS NDVI and NDWI for grassland drought assessment over the central Great Plains of the United States," Geophys. Res. Lett., vol. 34, no. 6, pp. 1-6, 2007.

[4]. L. Kumar and O. Mutanga, Google Earth Engine Applications. 2019.

[5]. A. Aghakouchak et al., "Reviews of geophysics remote sensing of drought: Progress, challenges," Rev. Geophys., vol. 53, pp. 1-29, 2015.

[6]. B.-C. Gao, "NDWI-A Normalized Difference Water Index for Remote Sensing of Vegetation Liquid Water From Space," Remote
Sens. Env., vol. 7212, no. April, pp. 257-266, 1996.

[7]. P. Ceccato, S. Flasse, S. Tarantola, S. Jacquemoud, and J. M. Grégoire, "Detecting vegetation leaf water content using reflectance in the optical domain," Remote Sens. Environ., vol. 77, no. 1, pp. 22-33, 2001.

[8]. Viện Quy hoạch Thủy lợi, "Báo cáo hiện trạng và phương hướng phát triển kinh tế xã hội."

[9]. Bộ Tài nguyên và Môi trường, "Thông tư số 14/2012/TT-BTNMT ban hành ngày 26/11/2012 về Quy định kỹ thuật điều tra thoái hóa đất," 2012.

\section{Summary}

Drought Monitoring during the dry season by NDDI index on Google Earth Engine, a case study at Dak Nong province

Tong Thi Huyen Ai, Nguyen Phuc Hai

Space Technology Institute, Vietnam Academy of Science and Technology,

Le Huu Dung

Branch of Land Registration Office, Co Do District, Can Tho City, Can Tho Province

Vo Hong Hien

Environment and Natural Resource Department of Ben Tre Province

Pham Thi Lan

Faculty of Geomatics and Land Administration, Hanoi University of Mining and Geology

In this study, the authors analyzed the relationship between the NDVI, NDWI, NDDI indexes and drought condition of Dak Nong province. Landsat images data in dry season from 2005-2019 quickly collected, pre-processed and calculated on Google Earth Engine. The results showed that NDWI and NDDI are more sensitive indicatior for drought than NDVI. In which, NDDI value $>0.8$ and NDWI $<0.1$ are areas with slight drought. The higher the NDDI index, the higher the ability of a drought phenomenon. Therefore, this NDDI can be used as an indicator for drought monitoring for Dak Nong province during the dry season. $\mathrm{O}$ 